\title{
INEQUITY IN BIOLOGIC DMARD PRESCRIPTION FOR SPONDYLOARTHRITIS ACROSS THE GLOBE: RESULTS FROM THE ASAS COMOSPA STUDY
}

E. Nikiphorou* ${ }^{1,2}$, D. van der Heijde ${ }^{2}$, S. Norton ${ }^{1}$, R. Landewé ${ }^{3}$, A. Moltót ${ }^{4,5}$, M. Dougados ${ }^{4,5}$, F. van den Bosch ${ }^{6}$, S. Ramiro ${ }^{2}$

${ }^{1}$ Department of Rheumatology, Leiden University Medical Center, Leiden, the Netherlands

${ }^{2}$ Academic Rheumatology Department, King's College London, London, United Kingdom

${ }^{3}$ Department of Clinical Immunology \& Rheumatology, Amsterdam Rheumatology Center, Amsterdam, the Netherlands

${ }^{4}$ Department of Rheumatology, Faculty of Medicine, Cochin Hospital \& Descartes University, Paris, France

${ }^{5}$ Inserm (U1153), clinical epidemiology and biostatistics, PRES Sorbonne Paris-Cité, Paris, France ${ }^{6}$ Ghent University Hospital, Ghent, Belgium

\section{Corresponding Author}

Elena Nikiphorou

Academic Rheumatology Department

King's College London

3.48 Weston Education,

Denmark Hill,

United Kingdom

email: enikiphorou@gmail.com

tel: +447990856425

WORD COUNT: $2610 \underline{2755}$

KEYWORDS: Spondyloarthritis; biologics; disease-modifying anti-rheumatic drugs; socioeconomic factors; comorbidities. 


\begin{abstract}
Objectives: The value of biologic DMARDs (bDMARDs) in SpA is well recognized but global access to these treatments can be limited due to high costs and other factors. This study explores country-variation in the use of bDMARDs in SpA in relation to country-level socio-economic factors.

Methods: Patients fulfilling the ASAS SpA criteria in the multi-national, cross-sectional ASAS COMOSPA study were studied. Current use of bDMARDs or conventional synthetic DMARDs (csDMARDs) was investigated, in separate models, with multilevel logistic regression analysis, taking the country level into account. Contribution of socio-economic factors including country health expenditures, gross domestic product (GDP) and human development index (HDI) as independent country-level factors, was explored individually, in models adjusted for sociodemographic as well as clinical variables.
\end{abstract}

Results: In total, 3370 patients from 22 countries were included (mean[SD] age 43[14] years; 66\% male; 88\% axial disease). Across countries, 1275 (38\%) were bDMARD users. Crude mean bDMARD-use varied between 5\% (China) to 74\% (Belgium). After adjustment for relevant sociodemographic and clinical variables, important variation in bDMARD-use across countries remained $(p<0.001)$. Country-level socio-economic factors, specifically higher health expenditures were related to higher bDMARD uptake, though not meeting statistical significance (OR $1.96 ; 95 \% \mathrm{Cl} 0.94,4.10)$. csDMARD uptake was significantly lower in countries with higher health expenditures (OR $0.32 ; 95 \% \mathrm{Cl} 0.15,0.65)$. Similar trends were seen with the other socio-economic variables.

Conclusions: There remains important residual variation across countries in bDMARD uptake of patients with SpA followed in specialized SpA centers. This is independent of well-known factors for bDMARD use such as clinical and country-level socio-economic factors. 


\section{INTRODUCTION}

2 The role of biological disease-modifying anti-rheumatic drugs (bDMARDs) in Spondyloarthritis

$3(\mathrm{SpA})$ has been extensively studied and robust scientific evidence supports their efficacy in

4 reducing disease activity and improving functional ability, spinal mobility and quality of life.[1]

5 bDMARDs are therefore recommended for use in the presence of active disease and following

6 failure of two non-steroidal anti-inflammatory drugs (NSAIDs).[2] However, an important barrier

7 to their use is their high cost which also influences the development of national guidelines and

8 prescribing patterns.

10 On the other hand, the use of conventional synthetic DMARDs (csDMARDs) in SpA, unlike 11 rheumatoid arthritis (RA) and other inflammatory arthritides with peripheral joint involvement is

12 less-well established. Currently there is a general lack of evidence on their role in axSpA,[3] and 13 the existing evidence consistently shows no efficacy[4-6] making their role debatable[7] and 14 resulting in the Assessment in SpondyloArthritis international Society (ASAS) and the European 15 League Against Rheumatism (EULAR) not supporting their use in patients with only axial 16 disease.[2]

Existing literature supports inequity in bDMARD prescription in RA, both at an individual and country level,[8-13] but the evidence for this is lacking in SpA. Increasing insight into patterns of treatment use across countries and potential differential access to biologic drugs can help highlight potential sources of inequity and drive change through informing service delivery, refining drug reimbursement criteria and access to these treatments nationally, in line with international recommendations. This is particularly important, since access and use of healthcare services that prevent and treat disease is one of the key determinants of health.[14] This study aimed to explore individual and country-level variation in the uptake of DMARDs in patients with $\mathrm{SpA}$ and unravel gaps in literature regarding how they are used and possible factors that could influence this. The ASAS COMOrbidities in SPondyloArthritis (COMOSPA) study, an

28 international study including patients from 22 countries and initially designed to estimate the 29 prevalence of comorbidities in $\mathrm{SpA},[15]$ provided an ideal setting to answer these questions. 
ASAS-COMOSPA is a multi-centre cross-sectional observational study with 22 participating countries across four continents (Africa, America, Asia and Europe).[15] Consecutive patients (age 18 years or over) with a clinical diagnosis of $\mathrm{SpA}$ according to the treating rheumatologist, either axial or peripheral, were included in ASAS-COMOSPA, provided they were able to understand and complete the questionnaires. For the present study, analyses were restricted to patients fulfilling the ASAS criteria for SpA, either axial or peripheral.[16] The study was conducted according to guidelines for good clinical practice in all countries with all local ethics committees approving the ASAS-COMOSPA study protocol. Written informed consent was obtained from all subjects before enrolment.

\section{Data collection}

Data collection in the ASAS-COMOSPA ranged from patient demographic variables to diseaserelated variables and treatment data, including: treatment with non-steroidal anti-inflammatory drugs (NSAIDs) with computation of the ASAS NSAID score (0-400)[17] reflecting NSAID-use over the past 3 months; current and past use of csDMARDs and bDMARDs (see below).

\section{Outcome measures}

The main outcome of interest was current bDMARD uptake, studied as a binary variable to indicate current bDMARD use versus all other (including csDMARD use and/or NSAIDs). In addition, current csDMARD uptake as a binary variable to indicate current cSDMARD use versus all other (including bDMARD use with or without csDMARDs and/or NSAID use) was also examined in separate models as another outcome measure.

\section{Individual-level variables}

Variables of interest potentially influencing the uptake of DMARDs, aside from age and gender, included socio-demographic factors such as educational status (secondary and university education vs primary education); HLA B27 status (positive vs negative); measures of disease activity such as the Ankylosing Spondylitis Disease Activity Score calculated with CRP (ASDAS); measures of functional ability (Bath Ankylosing Spondylitis Functional Index [BASFI], range 0-10); presence of axial vs peripheral disease (yes for axial disease); radiographic sacroiliitis (yes vs no); 
inflammatory bowel disease), (yes vs no) and comorbidity burden using the Rheumatic Disease

66 Comorbidity Index (RDCl, range 0-9).[18]

\section{Country-level variables}

69 Country socio-economic variables were studied as the main independent variables of interest and

70 included: country health expenditures per capita[19] (adjusted for purchasing power parity [PPP],

71 measured in international dollars); gross domestic product (GDP)[20] (adjusted for PPP, measured

72 in international dollars); Gini index[21,22], as a measure of income inequality across a country

73 (range 0 [absolute equality]-100 [absolute inequality]); human development index (HDI)[23], a

74 composite measure of average achievement in key dimensions of human development used to

75 rank countries based on their performance in these. These variables were split into tertiles with

76 the top two compared to the bottom tertile in regression analyses: for country health

77 expenditures, GDP and Gini, high/medium versus low. For HDI, an external classification system

78 was used[23] as opposed to creating a new dichotomization, with categories compared being

79 high/very high versus medium. All country-level socioeconomic variables are presented in the

80 supplementary table 1 . The country health expenditures variable was a priori chosen as the main

81 independent variable of interest, as the outcome refers to uptake of a drug, falling into health

82 expenditures. Therefore, we hypothesized that country health expenditures would be the most

83 relevant socio-economic variable in the context of health spending and a good reflection of

84 country wealth.

\section{Data analysis}

87 Multilevel modeling analyses were conducted in order to account for patients being recruited 88 from different countries. Multilevel models take into account the dependency of the 89 observations, in this instance by accounting for the two-level structure in the data, namely patients at the 'lower' level are nested within countries at the 'higher' level.[24] Multi-level mixed effects logistic regression models with random intercept for country were constructed with current use of bDMARDs and current use of csDMARDs as the dependent variables, in separate models. Odds ratios (ORs) and 95\% Confidence Intervals (CI) were estimated. Variations in impact of patient-level socio-demographic variables (age, gender and educational status) on DMARD use across countries were first tested by incorporating random slopes for the variable, which is 
education was found to vary significantly $(p<0.001)$ across countries in relation to bDMARD uptake; therefore, education was included with a random slope in multivariable models where bDMARD was the outcome to control for potential confounding at the country as well as individual level. Potential confounders were entered in the models in a manual forward procedure (cut-off $p<0.05$ ) provided they were meaningful in the univariable analyses (defined as $p<0.10$ ) or if considered clinically relevant. In a final step, the contribution of country health expenditures, GDP, Gini and HDI as independent country level factors, was individually explored in models adjusted for socio-demographic (age, gender, education level) as well as clinical variables (presence of axial vs peripheral disease, disease activity, sacroiliitis on X-ray, history of extraarticular manifestations, total NSAID score, past cs/bDMARD use) known to determine bDMARDuse (or csDMARD use, respectively) in SpA. All analyses were conducted with the statistical

\section{RESULTS}

\section{Patient, disease characteristics and treatment}

112 From a total of 3984 patients included in ASAS-COMOSPA across 22 countries, 3370 (85\%) fulfilled 113 the ASAS SpA criteria for axial or peripheral disease and were included in this study. The majority 114 of patients were male (66\%); mean age was 43 years (SD 14), mean disease duration 8.4 years (SD 115 9.5) and $88 \%$ had axial disease. Table 1 summarizes the patient demographics, clinical 116 characteristics and type of treatment used. Results by individual country are shown in 117 supplementary table 2. Across countries, 1275 (38\%) patients were bDMARD users, 1168 (35\%) csDMARD users ( $25 \%$ without bDMARDs). Crude mean bDMARD and csDMARD uptake varied considerably across countries (see figure 1).

\section{bDMARD uptake}

Table 2 shows the model with bDMARD uptake as the outcome. Higher country health expenditure was associated with higher bDMARD uptake (OR 1.96; 95\% $\mathrm{Cl} 0.94,4.10$ ), though without reaching statistical significance. In the same models, past b/csDMARD use was associated with almost double odds of using bDMARDs. Similarly, male gender, presence of axial (vs peripheral) disease, sacroiliitis on X-ray and presence of extra-articular manifestations were all significantly associated with higher bDMARD use. The results also suggest an association between 
nature of the study (i.e. simply an observation of less disease activity in those already on bDMARDs). Figure 1 shows the crude and adjusted percentage of bDMARD uptake by country. The model demonstrated significant variation in bDMARD use by country $(p<0.001)$ despite full adjustment.

\section{csDMARD uptake}

Table 3 shows the model with csDMARD uptake as the outcome. Higher country health expenditure was associated with lower csDMARD uptake (OR 0.32; $95 \% \mathrm{CI} 0.15,0.65)$. The results of the cSDMARD model are complimentary to those of the bDMARD model, with the same variables demonstrating an association with csDMARD uptake in the opposite direction to those of bDMARD uptake. In other words, male gender, axial disease and sacroiliitis on X-ray and past CSDMARD use were all significantly associated with lower csDMARD use. Higher disease activity was associated with higher csDMARD use, again likely to be a reflection of the cross-sectional nature of the study (i.e. higher disease activity in those using csDMARDs). Figure 2 shows the crude and adjusted percentage of csDMARD uptake by country. A significant variation across countries was also seen in relation to csDMARD uptake $(p<0.001)$ and also independent of adjustment for socio-demographic, clinical and socio-economic relevant variables.

\section{Other country-level socio-economic variables}

Across other socio-economic variables studied, the only significant association in univariable analyses was between HDI and csDMARD uptake. Replacing country health expenditures in the final adjusted models with other country-level socio-economic variables revealed higher use of bDMARDs and lower use of csDMARDs with higher GDP and HDI, although significance was only reached for GDP and csDMARD use (OR 0.44; 95\%Cl 0.21,0.91) (Table 4). Higher country-income inequality as measured by Gini was associated with lower bDMARD than csDMARD uptake, although no statistical significance was reached (Table 4).

\section{DISCUSSION}

The ASAS-COMOSPA study enabled the systematic study of b- and cs-DMARD uptake across 22 countries. It demonstrates important residual variation, which is not explained by sociodemographic and clinical characteristics. The study suggests that country-level socio-economic indicators may in part, but not entirely, explain some of the differences. The csDMARD findings are supportive of the bDMARD results, highlighting that higher country welfare seems to be 
associated not only with higher bDMARD use (although not reaching statistical significance), independent of all other characteristics including country of residence, but also with lower csDMARD use. Given the lack of evidence for efficacy of csDMARDs in axSpA[3] and the available evidence consistently showing no efficacy, $[2,4-7]$ this reflects an unjust selection of treatment for patients in countries of lower socio-economic welfare, based on decisions other than clinical indication.

bDMARD use was almost double in countries with higher compared to lower country health expenditures. Although not reaching statistical significance, the effect is of interest, since power to detect country level predictors is driven largely by the number of countries. The number of countries included in ASAS-COMOSPA, though impressive for a multinational study with the logistic challenges it represents, is relatively small in statistical terms and a limiting factor when analyzing country-level variables. This, in turn, is reflected in a lack of power to identify potentially significant relationships.

To date, only few studies have systematically studied access to biologics across countries and these have been mainly in RA.[8-13] Our study observations find support in the existing literature of bDMARD use in RA which suggests country-level socioeconomic factors to play a role.[11,13,25,26] In particular, existing evidence shows that patients living in countries with a higher welfare have lower disease activity states, likely to be at least in part mediated by a higher likelihood of receiving bDMARDs.[13] The high costs of these drugs have undoubtedly influenced reimbursement but also national recommendations and guidelines across countries, in order to regulate access to these treatments while keeping a balance between clinical and economic demands. $[27,28]$ Indeed, costs of bDMARDs vary widely by country, driven by socio-economic welfare among other factors [10] with countries of lower socio-economic welfare have been show to have_demonstrating stricter eligibility criteria for bDMARDsin RA.[12]

The existence of international recommendations in $\mathrm{SpA}[29]$ encourage comparable management in these patients. In fact, evidence suggests that most national recommendations follow the international ASAS recommendations and despite some countries requiring, for example, additional objective signs of inflammation and/or more pre-treatment, limiting access, general consensus exists about the use of, for example, TNF-inhibitor therapies.[30] Still, there could be 
'hidden' barriers across individual countries limiting access to these drugs, ranging from 194 differences in the funding of health-care provision, to local/regional variation in budget 195 availability and feasibility of access to these more expensive, albeit more effective treatments, 196 through to differences in guideline interpretation and personal approach as well as preference by 197 the treating rheumatologist._ It may be, for example, that knowledge about the potential side 198 effects of bDMARDs poses resistance to their use by some individuals, who may in turn seek out 199 to alternative treatments. This may explain the differences observed even between countries 200 with comparable health expenditures. We can only speculate on the reasons for the residual 201 degree of variation in bDMARD uptake in our study, despite adjustment for patient, disease and 202 country-level characteristics. It is also possible that patient selection at inclusion into the study 203 may have played a role in these observations. For example, preferential review of patients on 204 bDMARDs by some centers would not provide an accurate reflection of the wider practice at a 205 specific clinical setting and less so across the entire country. Furthermore, it is possible that not 206 always consecutive patients may have been selected for inclusion into the study. The fundamental 207 issue though remains that, assuming the patient needs for bDMARD use are similar across 208 countries, differential access to these treatments raises concerns regarding the risk of inequity.

210 Male patients, presence of axial disease, sacroiliitis on X-ray and presence of extra-articular 211 disease were all associated with higher bDMARD use. In the csDMARD model, these associations 212 were reversed and therefore supportive of the bDMARD findings. These observations are 213 reassuring, since all these factors are indicators of worse disease or better response and justify 214 higher bDMARD use.[31-33]

216 The study has some important limitations. Firstly, selection bias cannot be excluded and the 217 uptake of bDMARDs in the group of patients included per country may not be fully representative 218 of the general bDMARD uptake across all SpA patients. More specifically, the study has been 219 conducted in centers that are associated with ASAS and this may be a bias towards higher 220 bDMARD prescription, independent of the country and related socio-economic factors. Better 221 selection of patients for bDMARD use is possible in ASAS centers. This reflects potential sources 222 of bias to the findings of the study. However, consecutive patients were included in the study and 223 the disease characteristics of the population studied is reflective of a typical SpA population. 224 Secondly, it was not possible to explore all possible reasons for barriers to access of bDMARDs 
and as mentioned above, explanations for the residual variation seen in bDMARD use after 226 adjusting for socio-economic, socio-demographic and clinical variables remain speculative. The 227 aim, however, was to investigate whether differential access could be a problem and potentially 228 leading to inequities. Further research should unveil possible other explanations for treatment 229 choices. Furthermore, the cross-sectional nature of ASAS-COMOSPA precludes the study of causal 230 links; instead, it only allows for associations to be seen. Finally, the cross-sectional nature of the 231 analysis prevents the adjustment of disease activity before the start of bDMARDs, another 232 important limitation.

234 Important strengths of the study include the large patient numbers and the uniqueness of ASAS235 COMOSPA as one of the largest multi-national SpA datasets to date, which includes a wealth of 236 information ranging from socio-demographic, to disease-related clinical and radiographic measures of disease as well as country-level macro-economic data. The study population is typical and representative for SpA, characterized by predominantly male patients with an average age in the early 40s. The occurrence of disease at the peak of the productive lifespan of young individuals[34,35] with the known considerable impact on work ability[36] makes it imperative that access to treatments that are known to be effective in suppressing inflammation is feasible and unrestricted. This, alone, makes our study particularly relevant.

244 In conclusion, this study provides insights into complex contributions between patient and disease-related factors and country-level socio-economic factors, raising concerns regarding equity in access to effective (biologic) treatments in SpA. The findings suggest unequal and unjust selection of treatment for SpA independent of clinical indication, an observation that necessitates

248 urgent attention on the health equality and public health agenda.

COMPETING INTERESTS:

252 The authors declare they have no conflicts of interest relating to this study. 
The authors take responsibility for the integrity of the work, from inception to published article and they should indicate that they had full access to all the data in the study and take responsibility for the integrity of the data and the accuracy of the data analysis.

\section{ACKNOWLEDGEMENTS:}

260 The COMOSPA study was conducted under the umbrella of the International Society for Spondyloarthritis Assessment (ASAS).

\section{Collaborators:}

Fadoua Allali MD, MOROCCO;Raquel Almodovar González MD, SPAIN; Elena Alonso Blanco-Morales MD, SPAIN; Alejandro Alvarellos MD, Argentina; Maria Aparicio Espinar MD, SPAIN; Pamir Atagunduz MD, TURKEY; Pauline Bakker MD, NETHERLANDS; Juan C. Barreira MD. Argentina; Leila Benbrahim MD, MOROCCO; Bahia Benchekroun MD, MOROCCO; Alberto Berman MD, ARGENTINA; Juergen Braun MD, GERMANY; Alain Cantagrel MD PhD, FRANCE; Roberto Caporali MD, ITALY; Pedro Carvalho MD, PORTUGAL; Gustavo Casado MD, ARGENTINA; James Cheng-Chung Wei MD, PhD, TAWIAN; Francisco Colombres MD, ARGENTINA; Eugenio del Miguel Mendieta MD PhD, SPAIN; Juan D. Diaz-Garcia MD, MEXICO; Michel De Bandt MD PhD, FRANCE; Vanesa Duarte MD, ARGENTINA; Cristina Fernandez Carballido MD, SPAIN; Mari Cruz Fernandez Espartero MD, SPAIN; Manuel Fernandez-Prada MD, SPAIN; Rene-Marc Flipo MD PhD, FRANCE; Pilar Font Ugalde MD. PhD, SPAIN; Philippe Gaudin MD PhD, FRANCE; Philippe Goupille MD, FRANCE; Dolors Grados Cánovas MD, SPAIN; Jordi Gratacós Masmitjá MD PhD, SPAIN; Vittorio Grosso MD, ITALY; Naomi Ichikawa, MDJAPAN; Hisashi Inoue MD, JAPAN; Yuko Kaneko MD PhD, JAPAN; Taku Kawasaki MD PhD, JAPAN; Shigeto Kobayashi MD, JAPAN; Manjari Lahiri MD, SINGAPORE; Hernán Maldonado-Ficco MD, ARGENTINA; Marhadour MD, FRANCE; Alejandro Martínez MD, ARGENTINA; Kazuo Matsui MD, JAPAN; Ramón Mazzuchelli Esteban MD, SPAIN; Corinne Micelli MD PhD, FRANCE; Chisun Min MD, JAPAN; Mitsuhiro Morita MD PhD, JAPAN; Juan Mulero Mendoza MD PhD, SPAIN; Jose Raul Noguera Pons MD, SPAIN; Masato Okada MD, JAPAN; Alberto Ortiz MD, ARGENTINA; Jon Packham DM FRCP, UNITED KINGDOM; Gisela Pendón MD, ARGENTINA; Dora Pereira MD, ARGENTINA; José A Pereira da Silva MD, PORTUGAL; Fernando Pimentel-Santos MD, PORTUGAL; Hanan Rkain, MD MOROCCO; Oscar Rillo MD, ARGENTINA; Carlos Rodriguez Lozano MD, SPAIN; Adeline Ruyssen-Witrand MD PhD, FRANCE; Adrián Salas MD, ARGENTINA; Carlos Salinas-Ramos MD, MEXICO; Amelia Santosa MD, SINGAPORE; Alain Saraux MD PhD, FRANCE; Raj Sengupta FRCP PGCME, UNITED KINGDOM; Stefan Siebert PhD, UNITED KINGDOM; Martin Soubrier MD PhD CHU, FRANCE; Caroline Spiegel, GERMANY; Carmen Stolwijk MD, NETHERLANDS; Kurisu Tada MD, JAPAN; Naoho Takizawa MD, JAPAN; Yoshinori Taniguchi MD PhD, JAPAN; Atsuo Taniguchi MD PhD, JAPAN; Chung Tei Chou MD, TAIWAN; LayKeng Teoh SINGAPORE; Tetsuya Tomita MD PhD, JAPAN; Wen-Chan Tsai MD, PhD, TAIWAN; Shigeyoshi Tsuji MD PhD, JAPAN; Olga Tsyplenkova, GERMANY; Astrid van Tubergen MD PhD, NETHERLANDS; Kiana Vakil-Gilani BS, MPH, USA; Rafael Valle-Oñate MD, COLOMBIA; Gaelle Varkas MD, BELGIUM; Virginia Villaverde MD, SPAIN; Ai Yap SINGAPORE; 
The COMOSPA study was conducted with the financial support of $A b b v i e^{\circledR}, \mathrm{Pfizer}^{\circledast}$ and UCB ${ }^{\circledR}$, who provided an unrestricted grant to ASAS to fund the study. The funders did not have any role in the design or conduct of the study. This ancillary study did not receive any funding and the sponsors of COMOSPA did not have any interference with this current study.

\section{REFERENCES}

2991 Sepriano A, Regel A, van der Heijde D, et al. Efficacy and safety of biological and targetedsynthetic DMARDs: a systematic literature review informing the 2016 update of the ASAS/EULAR recommendations for the management of axial spondyloarthritis. $R M D$ Open 2017;3:e000396. doi:10.1136/rmdopen-2016-000396

2 van der Heijde D, Ramiro S, Landewé R, et al. 2016 update of the ASAS-EULAR management recommendations for axial spondyloarthritis. Ann Rheum Dis 2017;76:97891. doi:10.1136/annrheumdis-2016-210770

Regel A, Sepriano A, Baraliakos X, et al. Efficacy and safety of non-pharmacological and non-biological pharmacological treatment: a systematic literature review informing the 2016 update of the ASAS/EULAR recommendations for the management of axial spondyloarthritis. RMD open 2017;3:e000397. doi:10.1136/rmdopen-2016-000397

4 van den Berg R, Baraliakos X, Braun J, et al. First update of the current evidence for the management of ankylosing spondylitis with non-pharmacological treatment and nonbiologic drugs: a systematic literature review for the ASAS/EULAR management recommendations in ankylosing spondylitis. Rheumatology (Oxford) 2012;51:1388-96. doi:10.1093/rheumatology/kes066

5 Chen J, Veras MM, Liu C, et al. Methotrexate for ankylosing spondylitis. In: Chen J, ed. Cochrane Database of Systematic Reviews. Chichester, UK: : John Wiley \& Sons, Ltd 2013. CD004524. doi:10.1002/14651858.CD004524.pub4

6 Chen J, Lin S, Liu C. Sulfasalazine for ankylosing spondylitis. In: Chen J, ed. Cochrane Database of Systematic Reviews. Chichester, UK: : John Wiley \& Sons, Ltd 2014. CD004800. doi:10.1002/14651858.CD004800.pub3

Landewé RBM. Conventional DMARDs in axial spondyloarthritis: wishful—rather than rational-thinking! Ann Rheum Dis 2015;74:951-3. doi:10.1136/annrheumdis-2014206758 
3248 Kobelt, G KF. Access to innovative treatments in rheumatoid arthritis in Europe. A report 325 prepared for the European Federation of Pharmaceutical Industry Associations. http://www.comparatorreports.se/Access to RA Treatments October 2009.pdf

Orlewska E, Ancuta I, Anic B, et al. Access to biologic treatment for rheumatoid arthritis in Central and Eastern European (CEE) countries. Med Sci Monit 2011;17:SR113.http://www.ncbi.nlm.nih.gov/pubmed/21455121 (accessed 3 Jun 2017). Putrik P, Ramiro S, Kvien TK, et al. Inequities in access to biologic and synthetic DMARDs across 46 European countries. Ann Rheum Dis 2014;73:198-206. doi:10.1136/annrheumdis-2012-202603

Putrik P, Sokka T, Ramiro S, et al. Impact of socioeconomic gradients within and between countries on health of patients with rheumatoid arthritis (RA): Lessons from QUEST RA. Best Pract Res Clin Rheumatol 2012;26:705-20. doi:10.1016/j.berh.2012.07.011 reimbursed biologic DMARDs across European countries. Are differences related to country's wealth? Ann Rheum Dis 2014;73:2010-21. doi:10.1136/annrheumdis-2013203819

Putrik P, Ramiro S, Keszei AP, et al. Lower education and living in countries with lower wealth are associated with higher disease activity in rheumatoid arthritis: results from the multinational COMORA study. Ann Rheum Dis 2016;75:540-6. doi:10.1136/annrheumdis-2014-206737 Determinants of Health - WHO.

Moltó A, Etcheto A, van der Heijde D, et al. Prevalence of comorbidities and evaluation of their screening in spondyloarthritis: results of the international cross-sectional ASASCOMOSPA study. Ann Rheum Dis 2016;75:1016-23. doi:10.1136/annrheumdis-2015208174

Rudwaleit M, van der Heijde D, Landewe R, et al. The development of Assessment of SpondyloArthritis international Society classification criteria for axial spondyloarthritis (part II): validation and final selection. Ann Rheum Dis 2009;68:777-83. doi:10.1136/ard.2009.108233 Dougados M, Paternotte S, Braun J, et al. ASAS recommendations for collecting, analysing and reporting NSAID intake in clinical trials/epidemiological studies in axial spondyloarthritis. Ann Rheum Dis 2011;70:249-51. doi:10.1136/ard.2010.133488 
18 England BR, Sayles H, Mikuls TR, et al. Validation of the rheumatic disease comorbidity index. Arthritis Care Res (Hoboken) 2015;67:865-72. doi:10.1002/acr.22456

19 Worldbank. Country Health Expenditures. http://data.worldbank.org/indicator/SH.XPD.PCAP.PP.KD?end=2013\&start=1995

20 GDP. www.imf.org

21 Gini. http://data.worldbank.org/indicator/SI.POV.GINI

22 UNDP. http://www.undp.org/content/undp/en/home.html

23 UNDP-HDI. http://hdr.undp.org/en/composite/HDI

24 Twisk JWR. Applied Multilevel Analysis.

25 Putrik P, Sokka T, Ramiro S, et al. Impact of socioeconomic gradients within and between countries on health of patients with rheumatoid arthritis (RA): lessons from QUEST RA. Best Pract Res Clin Rheumatol 2012;26:705-20. doi:10.1016/j.berh.2012.07.011

26 Hoebert JM, Mantel-Teeuwisse AK, van Dijk L, et al. Do rheumatoid arthritis patients have equal access to treatment with new medicines?: tumour necrosis factor-alpha inhibitors use in four European countries. Health Policy 2012;104:76-83. doi:10.1016/j.healthpol.2011.10.011

27 Pronk $\mathrm{MH}$, Bonsel GJ. Out-patient drug policy by clinical assessment rather than financial constraints? The gate-keeping function of the out-patient drug reimbursement system in The Netherlands. Eur J Health Econ 2004;5:274-7. doi:10.1007/s10198-003-0223-0

28 NICE Spondyloarthritis Guidelines. https://pathways.nice.org.uk/pathways/spondyloarthritis\#path=view\%3A/pathways/spo ndyloarthritis/managing-peripheral-spondyloarthritis-in-adults.xml\&content=viewnode\%3Anodes-choice-of-non-biological-therapy

29 van der Heijde D, Ramiro S, Landewé R, et al. 2016 update of the ASAS-EULAR management recommendations for axial spondyloarthritis. Ann Rheum Dis 2017;76:97891. doi:10.1136/annrheumdis-2016-210770 van den Berg R, Stanislawska-Biernat E, van der Heijde DMFM. Comparison of recommendations for the use of anti-tumour necrosis factor therapy in ankylosing spondylitis in 23 countries worldwide. Rheumatology 2011;50:2270-7. doi:10.1093/rheumatology/ker270

31 Baraliakos X, Listing J, von der Recke A, et al. The Natural Course of Radiographic Progression in Ankylosing Spondylitis: Differences Between Genders and Appearance of 
Characteristic Radiographic Features. Curr Rheumatol Rep 2011;13:383-7. doi:10.1007/s11926-011-0192-8

32 Ramiro S, Stolwijk C, van Tubergen A, et al. Evolution of radiographic damage in ankylosing spondylitis: a 12 year prospective follow-up of the OASIS study. Ann Rheum Dis 2015;74:52-9. doi:10.1136/annrheumdis-2013-204055 van der Heijde D, Ramiro S, Landewé R, et al. 2016 update of the ASAS-EULAR management recommendations for axial spondyloarthritis. Ann Rheum Dis 2017;76:97891. doi:10.1136/annrheumdis-2016-210770

34 Boonen A, van der Heijde D, Landewé R, et al. Costs of ankylosing spondylitis in three European countries: the patient's perspective. Ann Rheum Dis 2003;62:7417.http://www.ncbi.nlm.nih.gov/pubmed/12860729 (accessed 13 May 2017). 2006;78:4-11.http://www.ncbi.nlm.nih.gov/pubmed/17042055 (accessed 13 May 2017).

Table 1. Patient demographics, clinical characteristics and treatment in patients with $\mathrm{SpA}$ fulfilling 407 the ASAS classification criteria.

\begin{tabular}{|l|c|}
\hline & Mean (SD) or $\mathrm{n}(\%)$ \\
\hline Age, $\mathrm{n}=3334$ & $42.9(13.7)$ \\
\hline Disease duration (years), $\mathrm{n}=3342$ & $8.4(9.5)$ \\
\hline Male gender & $2221(66)$ \\
\hline HLA B27 positive, $\mathrm{n}=2733$ & $2082(76)$ \\
\hline Education level, $\mathrm{n}=3364$ & \\
\hline -Primary school or less & $421(13)$ \\
\hline -Secondary school & $1497(44)$ \\
\hline -University & $1446(43)$ \\
\hline BMI $\left(\mathrm{kg} / \mathrm{m}^{2}\right.$ ), $\mathrm{n}=3325$ & $26.1(5.7)$ \\
\hline
\end{tabular}




\begin{tabular}{|c|c|c|}
\hline Current or previous smoker, $\mathrm{n}=3365$ & $1565(46)$ & 408 \\
\hline Sacroiliiis on X-ray, $n=3190$ & $2406(75)$ & \\
\hline Sacroiliitis on MRI, $\mathrm{n}=1782$ & $1249(70)$ & 411 \\
\hline History of enthesitis, $n=3367$ & $1281(38)$ & \\
\hline History of dactylitis, $n=3368$ & $463(14)$ & 413 \\
\hline $\mathrm{CRP}(\mathrm{mg} / \mathrm{L}), \mathrm{n}=3208$ & $0.51(11)$ & \\
\hline Patient Global (0-10), n=3336 & $4.1(2.5)$ & \\
\hline BASDAI (0-10), $n=3352$ & $3.7(2.4)$ & \\
\hline BASFI (0-10), $n=3349$ & $31(2.7)$ & \\
\hline ASDAS (CRP), $n=3155$ & $2.0(1.1)$ & \\
\hline Axial involvement (+/- peripheral) & $2955(87.7)$ & \\
\hline History of uveitis, $\mathrm{n}=3368$ & $724(21)$ & \\
\hline History of psoriasis, $n=3369$ & $643(19)$ & \\
\hline History of IBD, $n=3366$ & $194(6)$ & \\
\hline Extra-articular manifestations (uveiitis, IBD, psoriasis) & $1369(41)$ & \\
\hline $\mathrm{RDCl}(0-9)$ & $0.7(1.1)$ & \\
\hline \multicolumn{3}{|l|}{ Treatment } \\
\hline -NSAID intake, $n=3363$ & $3025(90)$ & \\
\hline -NSAID total score (past 3 months) & $37(46)$ & \\
\hline -current b/csDMARD & $2114(63)$ & \\
\hline -current bDMARD & $1275(38)$ & \\
\hline -current csDMARD & $1168(35)$ & \\
\hline -current csDMARD only & $839(25)$ & \\
\hline
\end{tabular}

$B M I=B o d y$ mass index; $M R I=$ Magnetic Resonance Imaging; $C R P=C$-reactive protein; BASDAl=Bath Ankylosing Spondylitis

Disease Activity Index; BASFI= Bath Ankylosing Spondylitis Functional Index; ASDAS= Ankylosing Spondylitis Disease

418 Activity Score calculated with CRP; IBD=Inflammatory Bowel Disease; RDCl= Rheumatic Disease Comorbidity Index;

419 NSAID=Non-Steroidal Anti-inflammatory Drug; bDMARD=biologic Disease-Modifying Anti-Rheumatic Drugs; cSDMARD=

420 conventional synthetic Disease-Modifying Anti-Rheumatic Drug.

422 Table 2. Uptake of bDMARDs: association with socio-demographic, clinical and treatment 423 variables as well as indicators of the country socio-economic welfare. 


\begin{tabular}{|l|r|r|}
\hline \multicolumn{1}{|c|}{ Independent predictors } & Univariable analysis & Multivariable analysis \\
OR $(95 \% \mathrm{Cl})$ & OR $(95 \% \mathrm{Cl}) \mathrm{n}=2792$ \\
\hline $\begin{array}{l}\text { Country health expenditure } \\
\text { (high/medium vs low) }\end{array}$ & $1.71(0.84,3.50)$ & $1.96(0.94,4.10)$ \\
\hline Age (years) & $1.01(1.00,1.01)$ & $1.00(0.99,1.01)$ \\
\hline Male gender (vs females) & $1.18(1.01,1.39)$ & $1.26(1.04,1.53)$ \\
\hline Axial (vs peripheral) disease & $1.48(1.16,1.89)$ & $1.62(1.15,2.28)$ \\
\hline ASDAS & $0.82(0.76,0.89)$ & $0.80(0.73,0.87)$ \\
\hline Sacroiliitis on X-ray & $1.75(1.44,2.12)$ & $1.41(1.12,1.78)$ \\
\hline History of extra-articular manifestations & $1.46(1.25,1.70)$ & $1.31(1.08,1.58)$ \\
\hline Total NSAID score (0-400), last 3 months & $0.99(0.99,1.00)$ & $0.99(0.99,1.00)$ \\
\hline Past csDMARD use & $2.31(1.96,2.73)$ & $2.08(1.72,2.52)$ \\
\hline Past bDMARD use & $2.64(2.13,3.28)$ & $2.48(1.93,3.19)$ \\
\hline Education & $0.79(0.62,1.00)$ & $0.76(0.52,1.13)$ \\
\hline (secondary/university vs primary) & & \\
\hline & & \\
\hline
\end{tabular}

Table 3. Uptake of csDMARDs: association with socio-demographic, clinical and treatment 427

\begin{tabular}{|l|r|r|}
\hline \multicolumn{1}{|c|}{ Independent predictors } & \multicolumn{1}{c|}{$\begin{array}{c}\text { Univariable analysis } \\
\mathrm{OR}(95 \% \mathrm{Cl})\end{array}$} & $\begin{array}{c}\text { Multivariable analysis } \\
\text { OR }(95 \% \mathrm{Cl}) \mathrm{n}=2792\end{array}$ \\
\hline $\begin{array}{l}\text { Country health expenditure } \\
\text { (high/medium vs low) }\end{array}$ & $0.52(0.26,1.03)$ & $0.32(0.15,0.65)$ \\
\hline Age (years) & $1.01(1.00,1.02)$ & $1.00(1.00,1.01)$ \\
\hline Male gender (vs females) & $0.73(0.61,0.87)$ & $0.76(0.62,0.94)$ \\
\hline Axial (vs peripheral) disease & $0.30(0.24,0.39)$ & $0.31(0.23,0.44)$ \\
\hline ASDAS & $1.17(1.07,1.27)$ & $1.16(1.06,1.28)$ \\
\hline
\end{tabular}




\begin{tabular}{|l|r|r|}
\hline Sacroiliitis on X-ray & $0.53(0.43,0.65)$ & $0.74(0.58,0.94)$ \\
\hline $\begin{array}{l}\text { History of extra-articular } \\
\text { manifestations }\end{array}$ & $1.39(0.00,1.16)$ & $1.53(1.23,1.90)$ \\
\hline $\begin{array}{l}\text { Total NSAID score }(0-400) \text { in last } 3 \\
\text { months }\end{array}$ & $1.00(1.00,1.01)$ & $1.00(1.00,1.01)$ \\
\hline Past csDMARD use & $0.39(0.32,0.48)$ & $0.36(0.28,0.45)$ \\
\hline Past bDMARD use & $0.55(0.42,0.73)$ & $0.73(0.53,1.00)$ \\
\hline
\end{tabular}

428

429

430

Table 4. Relationship between country-level socio-economic factors and bDMARD and cSDMARD use, all tested individually in separate models (each cell represents a different model)

\begin{tabular}{|c|c|c|c|c|}
\hline & \multicolumn{2}{|c|}{ bDMARD use } & \multicolumn{2}{|c|}{ csDMARD use } \\
\hline & $\begin{array}{c}\text { Univariable } \\
\text { analysis } \\
\text { OR }(95 \% \mathrm{Cl})\end{array}$ & $\begin{array}{c}\text { Multivariable } \\
\text { analysis§ } \\
\text { OR }(95 \% \mathrm{Cl})\end{array}$ & $\begin{array}{c}\text { Univariable } \\
\text { analysis } \\
\text { OR }(95 \% \mathrm{Cl})\end{array}$ & $\begin{array}{c}\text { Multivariable } \\
\text { analysis } \pm \\
\text { OR }(95 \% \mathrm{Cl})\end{array}$ \\
\hline $\begin{array}{c}\text { GDP } \\
\text { (high/medium vs low) }\end{array}$ & $1.57(0.78,3.15)$ & $1.93(0.91,4.06)$ & $0.59(0.30,1.15)$ & $\begin{array}{c}0.44 \\
(0.21,0.91)^{*}\end{array}$ \\
\hline $\begin{array}{c}\text { Gini } \\
\text { (high/medium vs low) }\end{array}$ & $0.84(0.38,1.87)$ & $0.73(0.31,1.72)$ & $0.76(0.35,1.65)$ & $0.96(0.39,2.37)$ \\
\hline $\begin{array}{c}\mathrm{HDI} \\
\text { (very high/high vs } \\
\text { medium) }\end{array}$ & $2.16(0.64,7.27)$ & $2.12(0.62,7.31)$ & $\begin{array}{c}0.32 \\
(0.11,0.98)^{*}\end{array}$ & $0.29(0.08,1.07)$ \\
\hline
\end{tabular}

$439 G D P=$ Gross Domestic Product; Gini= measure of income inequality; HDI=Human Development Index

$440 \S$ Refers to the multivariable model presented in table 2 and in which the variable health expenditures was replaced by

441 the other country-level socio-economic factors, in separate models 
$442 \pm$ Refers to the multivariable model presented in table 3 and in which the variable health expenditures was replaced by

443 the other country-level socio-economic factors, in separate models

444

445

446 Figure 1: bDMARD uptake (\%) by country. Crude and adjusted percentage use shown along with

$44795 \% \mathrm{Cl}$ based on models with socio-economic, socio-demographic and clinical variables. Countries

448 ranked based on health expenditure: low (left) to high (right).

449

450 Figure 2. csDMARD uptake (\%) by country. Adjusted and crude percentage use shown along with $45195 \% \mathrm{Cl}$ based on models with socio-economic, socio-demographic and clinical variables. Countries 452 ranked based on health expenditure: low (left) to high (right). 